\title{
Comparison of blood pressure levels across the spectrum of hypertension related signs and symptoms in out patients.
}

1. MBBS, FCPS (Internal Medicine) Consultant Physician

Chiniot General Hospital Korang Karachi.

2. MBBS, FCPS (Adult Cardiology) Post Fellow Interventional Cardiology NICVD Karachi.

3. MBBS, M.Phil

Assistant Professor Pathology Liaquat College of Medicine and Dentistry Karachi.

4. MBBS, MCPS, FCPS (Medicine)

Assistant Professor Medicine Liaquat National Hospital and Medical College Karachi.

5. MBBS, M.Phil (Histopathology) Assistant Professor Pathology Al-Tibri Medical College Isra University Karachi.

6. FCPS

Post Graduate Trainee National Institute of Cardiovascular Diseases Karachi.

Correspondence Address:

Dr. Imtiaz Manzoor Consultant Physician

Chiniot General Hospital Korangi

Karachi.

imtiazmanzoor@yahoo.com

Article received on:

17/03/2020

Accepted for publication:

$15 / 06 / 2020$

\section{INTRODUCTION}

Hypertension or elevated blood pressure is a serious disease that considerably increases the risks of heart, brain, kidney and other systematic diseases. ${ }^{1}$ The systolic and diastolic blood pressures are the two important components of arterial blood pressure, representing pressure in blood vessels when the heart contracts or beats and the pressure in the vessels when the heart rests between beats, respectively. ${ }^{1}$ Hypertension is diagnosed when the systolic blood pressure reading is $\geq 140 \mathrm{mmHg}$ and the diastolic blood pressure reading is $\geq 90 \mathrm{mmHg}$ on two different occasions or days. ${ }^{1,2}$ Literature reports several risk factors for hypertension and cardiovascular diseases. Obesity, high salt intake, sedentary life style family history of hypertension, tobacco smoking high cholesterol levels and lack of physical activity are major risk factors for hypertension. ${ }^{1-4}$ Most of the time patients with hypertension remain undiagnosed due to lack of any warning signs or symptoms. ${ }^{1-3}$ The occult nature of disease make it important to screen the at risk individuals for hypertension even in absence of any relevant clinical signs and symptoms. Hence, regular evaluation of systolic and diastolic blood pressure by a trained health professional is important for assessment of risk and associated conditions. ${ }^{3,5}$ However, a wide spectrum of symptoms may occur as the disease progresses including early morning headaches, nosebleeds, irregular heart rhythms, vision changes, and buzzing in the ears. The rise in intensity of hypertension can cause fatigue, nausea, vomiting, confusion, anxiety, chest pain, and muscle tremors. ${ }^{1-3}$ Pakistan is a developing 
country which is facing a consistently increasing burden of non-communicable diseases including hypertension and other cardiovascular diseases. $^{6}$ In Pakistan, increased genetic susceptibility, environmental factors, female gender, urbanization, obesity and sedentary life style particularly among middle age population, cultural practices promoting sedentary life style in females are major risk factors for hypertension. ${ }^{7,8}$ However, studies from Pakistan identify gaps in knowledge related to hypertension irrespective of disease status. Nevertheless, people suffering from hypertension have relatively better knowledge and understanding about the risk factors and the disease..$^{9,10}$

A hospital based study conducted in Tehsil Head Quarter (THQ) Hospital of Hassan Abdal, Pakistan identifiedsevere lack of awareness among population presenting at clinics. The study found a considerable proportion of adult patients visiting in clinics were unaware of their diseases status. Similarly, poor complianceto hypertension treatment was reported by hypertensive patients aware of their diagnosis. ${ }^{11}$ Studies advocate that community perception about the hypertension as a disease, knowledge about signs and symptoms of hypertension and its complications are key factors in improving health seeking behaviour, self-care as well as disease outcomes. ${ }^{12-14}$

Moreover, knowledge regarding possible signs and symptoms related to hypertension can be crucial in improving health outcomes as that rise in blood pressure levels or its severity can be associated with specific signs and symptoms. ${ }^{15-19}$ Early identification and recognition of such signs and symptoms may result in reduction in hypertension related morbidity and mortality. Hence, this study aims to compare the blood pressure levels across the categories of hypertension related signs and symptoms among the patients of hypertension presenting in outpatients; aged up to 45 years.

\section{MATERIAL \& METHODS}

A cross-sectional survey was conducted among patients aged up to 45 years of age presenting in out-patient department of a secondary care hospital in Karachi, Pakistan. The study included all those patients who reported history of hypertension and were taking anti-hypertensive medications at the time of survey using convenient sampling technique. However, hypertensive patients were excluded from the study if they found to have any of the co-morbids; such as morbid obesity, diabetes mellitus, ischemic heart disease, neurological disorders, cluster headache, gastrointestinal disease, history of visual problems and epistaxis before being diagnosed with hypertension. Study participants were interviewed to collect the required information using structured questionnaire. The blood pressure of the study participants was also recorded with the help of sphygmomanometer and stethoscope. Data was collected using trained healthcare providers who were also well trained in blood pressure measurement. Informed consent was obtained from each study participant at the time of data collection. The approval for the conduct of this study in the hospital was directly obtained from the hospital administration while ethical approval was also obtained from Ethics Review Committee. This study was completed in a duration of 8 months.

Data was analyzed using SPSS version 20.After checking normality, Mann Whitney $U$ test was applied to identify any statistically significant differences in blood pressure levels among patients reporting selected clinical signs and symptoms in comparison to those who didn't report those symptoms. A sub-group analysis was also applied by dividing study participants divided into two groups on the basis of their duration of illness i.e. hypertensive with a diagnosis of five years or lesser duration and hypertensive with a diagnosis older than 5 years.

\section{RESULTS}

The study obtained data from 141 patients of hypertension. Among all the study participants $57.4 \%(n=81)$ were females. This study found that overall systolic blood pressure levels of study participants were significantly varied across the categories of history of headache $(p=0.045)$, sleep apnea $(p=0.043)$ and palpitation $(p=0.03)$. However, patients with history of headache 
had relatively higher mean rank for systolic blood pressure as compared to patients with no history of headache. On the contrary, study participants with sleep apnea and palpitation had higher mean rank of systolic blood pressure levels as compared to those who didn't had those symptoms. Moreover, the diastolic blood pressure levels were not significantly different among hypertensive patients as categorized on the basis of specified clinical signs and symptoms of hypertension (Table-I).

\begin{tabular}{|c|c|c|c|c|}
\hline \multirow{2}{*}{$\begin{array}{c}\text { Variables } \\
(n=141)\end{array}$} & $\begin{array}{l}\text { Systolic Blood } \\
\text { Pressure }\end{array}$ & \multirow{2}{*}{$\begin{array}{c}\mathrm{P}- \\
\text { Value }\end{array}$} & $\begin{array}{l}\text { Diastolic Blood } \\
\text { Pressure }\end{array}$ & \multirow{2}{*}{$\begin{array}{c}\text { P- } \\
\text { Value }\end{array}$} \\
\hline & Mean Rank & & Mean Rank & \\
\hline \multicolumn{5}{|c|}{ Smoking History } \\
\hline Yes & 89.64 & \multirow{2}{*}{0.208} & 85.36 & \multirow{2}{*}{0.331} \\
\hline No & 70.03 & & 70.25 & \\
\hline \multicolumn{5}{|c|}{ History of Headache } \\
\hline Yes & 67.62 & \multirow{2}{*}{0.045} & 69 & \multirow{2}{*}{0.235} \\
\hline No & 84.62 & & 79.05 & \\
\hline \multicolumn{5}{|l|}{ Vertigo } \\
\hline Yes & 69.62 & \multirow{2}{*}{0.673} & 69.97 & \multirow{2}{*}{0.751} \\
\hline No & 72.48 & & 72.11 & \\
\hline \multicolumn{5}{|l|}{ Edema } \\
\hline Yes & 68.96 & \multirow{2}{*}{0.603} & 71.55 & \multirow{2}{*}{0.888} \\
\hline No & 72.51 & & 70.59 & \\
\hline \multicolumn{5}{|c|}{ Chest Pain } \\
\hline Yes & 68.1 & \multirow{2}{*}{0.512} & 62.85 & \multirow{2}{*}{0.065} \\
\hline No & 72.7 & & 75.76 & \\
\hline \multicolumn{5}{|c|}{ Vision Problems } \\
\hline Yes & 75.18 & \multirow{2}{*}{0.226} & 75.77 & \multirow{2}{*}{0.167} \\
\hline No & 66.99 & & 66.43 & \\
\hline \multicolumn{5}{|c|}{ Dyspnea } \\
\hline Yes & 72.61 & \multirow{2}{*}{0.641} & 71.33 & \multirow{2}{*}{0.923} \\
\hline No & 69.46 & & 70.68 & \\
\hline \multicolumn{5}{|c|}{ Epistaxis } \\
\hline Yes & 86 & & 87.67 & \\
\hline No & 70.67 & 0.513 & 70.64 & 0.466 \\
\hline Increase & Urinary Freq & ency & & \\
\hline Yes & 71.92 & & 67.5 & \\
\hline No & 70.53 & 0.846 & 72.81 & 0.456 \\
\hline Nausea & & & & \\
\hline Yes & 78.41 & & 63.17 & \\
\hline No & 69.08 & 0.265 & 73.03 & 0.238 \\
\hline Sleep A & nea & & & \\
\hline Yes & 83.89 & & 76.92 & \\
\hline No & 67.37 & 0.043 & 69.33 & 0.352 \\
\hline Palpitati & & & & \\
\hline Yes & 81.69 & & 73.88 & \\
\hline No & 65.99 & 0.03 & 69.65 & 0.559 \\
\hline Fatigue & & & & \\
\hline Yes & 71.93 & 0664 & 72.81 & 0394 \\
\hline No & 68.66 & 0.664 & 66.42 & 0.394 \\
\hline Confusi & & & & \\
\hline Yes & 72.68 & & 68.95 & \\
\hline No & 68.53 & 0.547 & 74.02 & 0.461 \\
\hline
\end{tabular}

The sub-group analysis for the patients of hypertension with a diagnosis of five years or lesser duration this study found that systolic blood pressure levels were significantly varied across categories of sleep apnea $(p=0.021)$ and palpitation $(p=0.045)$ where patients with these clinical signs and symptoms had higher mean rank of systolic blood pressure levels. Moreover, the diastolic blood pressure level was significantly varied across the hypertensive with and without the symptom of chest pain $(p=0.048)$, Moreover, patients who didn't report the complain of chest pain were found to have higher mean rank of diastolic blood pressure levels (Table-II).

Furthermore, the sub-group analysis for the patients of hypertension with a diagnosis of more than five years found that the systolic and the diastolic blood pressure levels were not significantly different varied for any of the clinical sign and symptom included in this study (TableIII).

\section{DISCUSSION}

This study was a cross-sectional survey which was conducted in hospital setting in Karachi. This study assessed any significant variation in mean levels of blood pressure across the study participants who reported specific clinical sign and symptom in comparison to those who didn't report that clinical sign or symptom. This study particularly assessed these variations in mean blood pressure levels in relation toclinical symptoms such as; headache, palpitations, dyspnea, epistaxis, fatigue, neurological disorders, cluster headache, gastrointestinal disease, history of visual problems and epistaxis. This study found that history of headache, sleep apnea and palpitation were significantly reported by the hypertensive with relatively higher mean systolic blood pressures. Moreover, the diastolic blood pressure levels were not significantly different among hypertensive patients as categorized on the basis of specified clinical signs and symptoms of hypertension (Table-I). These findings are supported by previous studies. ${ }^{20,17} \mathrm{~A}$ study found significant differences in frequency of clinical symptoms among hypertensive. ${ }^{20}$ 


\begin{tabular}{|c|c|c|c|c|}
\hline \multirow{2}{*}{$\begin{array}{l}\text { Variables } \\
(n=110)\end{array}$} & $\begin{array}{l}\text { Systolic Blood } \\
\text { Pressure }\end{array}$ & \multirow[t]{2}{*}{$\mathbf{P}$} & $\begin{array}{l}\text { Diastolic Blood } \\
\text { Pressure }\end{array}$ & \multirow[t]{2}{*}{$\mathbf{P}$} \\
\hline & Mean Rank & & Mean Rank & \\
\hline \multicolumn{5}{|c|}{ Smoking History } \\
\hline Yes & 65.33 & \multirow{2}{*}{0.427} & 61.67 & \multirow{2}{*}{0.62} \\
\hline No & 54.93 & & 55.14 & \\
\hline \multicolumn{5}{|c|}{ Headache History } \\
\hline Yes & 53.91 & \multirow{2}{*}{0.211} & 53.58 & \multirow{2}{*}{0.132} \\
\hline No & 64.21 & & 66.03 & \\
\hline \multicolumn{5}{|l|}{ Vertigo } \\
\hline Yes & 55.67 & \multirow{2}{*}{0.954} & 54.7 & \multirow{2}{*}{0.782} \\
\hline No & 55.32 & & 56.36 & \\
\hline \multicolumn{5}{|l|}{ Edema } \\
\hline Yes & 56.03 & \multirow{2}{*}{0.871} & 56.61 & \multirow{2}{*}{0.734} \\
\hline No & 55.06 & & 54.58 & \\
\hline \multicolumn{5}{|c|}{ Chest Pain } \\
\hline Yes & 53.35 & \multirow{2}{*}{0.569} & 48 & \multirow{2}{*}{0.048} \\
\hline No & 56.83 & & 60.13 & \\
\hline \multicolumn{5}{|c|}{ Vision Problems } \\
\hline Yes & 61.7 & \multirow{2}{*}{0.062} & 60.83 & \multirow{2}{*}{0.11} \\
\hline No & 50.52 & & 51.22 & \\
\hline \multicolumn{5}{|c|}{ Dyspnea } \\
\hline Yes & 58.81 & \multirow{2}{*}{0.283} & 54.91 & \multirow{2}{*}{0.848} \\
\hline No & 52.42 & & 56.05 & \\
\hline Epistaxi & & & & \\
\hline Yes & 68.67 & & 70.33 & \\
\hline No & 55.13 & 0.494 & 55.08 & 0.430 \\
\hline Increase & Urinary Freq & ency & & \\
\hline Yes & 56 & م०० & 53.1 & $0=10$ \\
\hline No & 55.21 & 0.099 & 56.87 & 0.040 \\
\hline Nausea & & & & \\
\hline Yes & 61.7 & 0 & 49.36 & (205 \\
\hline No & 53.68 & $0 .<00$ & 57.31 & 0.200 \\
\hline Sleep A & & & & \\
\hline Yes & 70.05 & Q? & 56.18 & 0915 \\
\hline No & 52.27 & $0.0<1$ & 55.35 & 0.915 \\
\hline Palpitati & & & & \\
\hline Yes & 64.41 & 0045 & 56.25 & 0867 \\
\hline No & 51.51 & 0.040 & 55.16 & 0.007 \\
\hline Fatigue & & & & \\
\hline Yes & 56.57 & $50 ?$ & 57.43 & 0333 \\
\hline No & 53.12 & 0.052 & 51.18 & 0.000 \\
\hline Confusi & & & & \\
\hline Yes & 58.08 & 0204 & 53.45 & 0120 \\
\hline No & 52.17 & $0.3<4$ & 58.15 & 0.400 \\
\hline & $\begin{array}{l}\text {-II. Blood pr } \\
\text { manifestatic } \\
\text { (Up to } 5\end{array}$ & $\begin{array}{l}\text { sure le } \\
\text { of hy } \\
\text { ars du }\end{array}$ & $\begin{array}{l}\text { els and clinic } \\
\text { ertension } \\
\text { ation). }\end{array}$ & \\
\hline
\end{tabular}

\begin{tabular}{|c|c|c|c|c|}
\hline \multirow{2}{*}{$\begin{array}{c}\text { Variables } \\
(n=31)\end{array}$} & $\begin{array}{l}\text { Systolic Blood } \\
\text { Pressure }\end{array}$ & \multirow[t]{2}{*}{$\mathbf{P}$} & $\begin{array}{l}\text { Diastolic Blood } \\
\text { Pressure }\end{array}$ & \multirow{2}{*}{$P^{*}$} \\
\hline & Mean Rank & & Mean Rank & \\
\hline \multicolumn{5}{|c|}{ Smoking History } \\
\hline Yes & 29 & \multirow{2}{*}{0.194} & 28.5 & \multirow{2}{*}{0.194} \\
\hline No & 15.57 & & 15.58 & \\
\hline \multicolumn{5}{|c|}{ Headache History } \\
\hline Yes & 14.1 & \multirow{2}{*}{0.123} & 16.5 & \multirow{2}{*}{0.699} \\
\hline No & 19.45 & & 15.09 & \\
\hline \multicolumn{5}{|l|}{ Vertigo } \\
\hline Yes & 14.72 & \multirow{2}{*}{0.423} & 15.69 & \multirow{2}{*}{0.861} \\
\hline No & 17.37 & & 16.33 & \\
\hline \multicolumn{5}{|l|}{ Edema } \\
\hline Yes & 12.55 & \multirow{2}{*}{0.147} & 16.05 & \multirow{2}{*}{0.983} \\
\hline No & 17.64 & & 15.98 & \\
\hline \multicolumn{5}{|c|}{ Chest Pain } \\
\hline Yes & 15.45 & \multirow{2}{*}{0.819} & 15.85 & \multirow{2}{*}{0.95} \\
\hline No & 16.26 & & 16.07 & \\
\hline \multicolumn{5}{|c|}{ Vision Problems } \\
\hline Yes & 15.1 & \multirow{2}{*}{0.476} & 15.3 & \multirow{2}{*}{0.583} \\
\hline No & 17.64 & & 17.27 & \\
\hline \multicolumn{5}{|l|}{ Dyspnea } \\
\hline Yes & 14.66 & \multirow{2}{*}{0.401} & 16.66 & \multirow{2}{*}{0.682} \\
\hline No & 17.43 & & 15.3 & \\
\hline Epistaxis & & & & \\
\hline Yes & $\ldots \ldots$ & & $\ldots \ldots$ & \\
\hline No & $\ldots .$. & & $\ldots \ldots$ & $\cdots$ \\
\hline Increase & Urinary Frequ & ency & & \\
\hline Yes & 16.38 & 0012 & 15.56 & 877 \\
\hline No & 15.87 & 0.912 & 16.15 & 0.871 \\
\hline Nausea & & & & \\
\hline Yes & 18.12 & ०620 & 15 & 0812 \\
\hline No & 15.69 & $0.0<9$ & 16.15 & 0.042 \\
\hline Sleep Ap & & & & \\
\hline Yes & 16.5 & 0823 & 18.23 & 0317 \\
\hline No & 15.72 & $0.8<3$ & 14.78 & 0.317 \\
\hline Palpitatic & & & & \\
\hline Yes & 18.05 & 0350 & 17.41 & 528 \\
\hline No & 14.88 & 0.309 & 15.22 & $0.5<0$ \\
\hline Fatigue & & & & \\
\hline Yes & 15.92 & 0942 & 15.82 & 0827 \\
\hline No & 16.33 & 0.942 & 16.75 & $0.0<1$ \\
\hline Confusio & & & & \\
\hline Yes & 15.7 & 781 & 15.52 & 0654 \\
\hline No & 16.72 & 0.101 & 17.17 & 0.004 \\
\hline *Exact $\mathrm{S}$ & ificance & & & \\
\hline $\begin{array}{r}\text { Tab } \\
\text { manifes }\end{array}$ & $\begin{array}{l}\text { III. Blood p } \\
\text { ions of hyp }\end{array}$ & $\begin{array}{l}\text { sure le } \\
\text { ension }\end{array}$ & $\begin{array}{l}\text { els and cli } \\
>5 \text { years } 0\end{array}$ & ion). \\
\hline
\end{tabular}


A study conducted in Germany also supports that symptoms like dizziness and headache are closely related to blood pressure levels in untreated and treated hypertensive. However, these findings are contrary to a previous study conducted by Noel and colleagues who failed to find no relation between hypertension and clinical symptoms of headache, epistaxis, and tinnitus. ${ }^{21}$ The variable findings in different studies can be explained by the differences in study methodologies, particularly differences in inclusion and exclusion criteria. Furthermore, in this study high mean of systolic blood pressure can attributed to white coat or Labile hypertension as the data was conducted from patients in hospital settings during follow-up visit. ${ }^{22,23}$

This study has some methodological limitations. First, this study was conducted in hospital settings where patients coming to OPD were invited to participate in the study. The use of convenient sampling while selecting of followup patients from OPD might have introduced volunteer bias resulting in enrolling patients who were more concerned and responsive towards any kind of clinical symptoms ever experienced by them despite currently ell controlled blood pressures. This might have resulted in failure to find any statistically significant differences among most of comparison groups compared on the basis of reporting presence or absence of a specified clinical sign and symptom. Secondly, the blood pressure readings of study participant were recorded only once by trained health care workers. However, taking more than one reading and using mean of two or more measurements taken at the same time reduces the intra-observer bias and any misleading blood pressure recording by chance. ${ }^{24}$ Furthermore, hypertensive patients with the history of under nutrition, specifically common vitamin deficiencies such as Vitamin $A$ and Vitamin B deficiencies were not excluded from the study which might have resulted in over reporting of related clinical signs and symptoms. Further research is required with more robust scientific methodology to assess the possible relation between blood pressure levels and occurrence of various systematic clinical manifestations.

\section{CONCLUSION}

Blood pressure levels were found to be significantly different across categories of a number of clinical manifestations of hypertension. Moreover, the observed differences differed among patients with different durations of hypertension.

\section{Conflict of Interests}

The authors report no conflict of interests.

Copyright $@ 15$ June, 2020.

\section{REFERENCES}

1. World Health Organization. Hypertension. Available at URL: https://www.who.int/news-room/fact-sheets/ detail/hypertension. [Last visited 12th Dec, 2019].

2. Web MD Hypertension. Available at URL: https://www. webmd.com/hypertension-high-blood-pressure/ default. htm [Last visited on 12th Dec, 2019].

3. World Health Organization. Silent killer, global public health crisis. World Health Day. Geneva: WHO; 2013A global brief on hypertension. Available from URL: http://www.ishworld.com/downloads/pdf/global_brief_ hypertension.pdf [Last accessed on Dec 20th, 2019].

4. Devadason $P$, Sabarinath $M$, Reshma Dass $R$, Sameena A, Sanjeetha Fathima S, Mathiarasu AM, Kulasekharam KD. Risk factors for Hypertension and its complications-A Hospital based case control study. International Journal of Interdisciplinary and Multidisciplinary Studies (IJIMS). 2014; 1(4):160-3.

5. Danninger K, Hafez A, Binder RK, Aichberger M, Hametner B, Wassertheurer S, Weber T. High prevalence of hypertension and early vascular aging: A screening program in pharmacies in Upper Austria. Journal of human hypertension. 2019 Jul 29:19.

6. Ahmad K, Jafar TH. Prevalence and determinants of blood pressure screening in Pakistan. Journal of hypertension. 2005 Nov 1; 23(11):1979-84.

7. Aziz KU. Evolution of systemic hypertension in Pakistani population. J Coll Physicians Surg Pak. 2015 Apr 1; 25(4):286-91.

8. Zafar SN, Gowani SA, Irani FA, Ishaq M. Awareness of the risk factors, presenting features and complications of hypertension amongst hypertensives and normotensives. J Pak Med Assoc. 2008 Dec; 58(12):711-5. 
9. Shafi ST, Shafi T. A survey of hypertension prevalence, awareness, treatment, and control in health screening camps of rural central Punjab, Pakistan. Journal of epidemiology and global health. 2017 Jun 1; $7(2): 135-40$.

10. Almas A, Godil SS, Lalani S, Samani ZA, Khan AH. Good knowledge about hypertension is linked to better control of hypertension; A multicentre cross sectional study in Karachi, Pakistan. BMC research notes. 2012 Dec; 5(1):579.

11. Ilyas N, Rahim K, Waqar A. Hypertension; silent killer. Professional Medical Journal. 2015 Apr 1;22(2).

12. Lloyd-Jones DM, Evans JC, Levy D. Hypertension in adults across the age spectrum: current outcomes and control in the community. Jama. 2005 Jul 27; 294(4):466-72.

13. Nyaaba GN, Masana L, Aikins AD, Stronks K, Agyemang C. Lay community perceptions and treatment options for hypertension in rural northern Ghana: A qualitative analysis. BMJ open. 2018 Nov 1; 8(11):e023451.

14. Naheed A, Haldane V, Jafar TH, Chakma N, LegidoQuigley $\mathrm{H}$. Patient pathways and perceptions of hypertension treatment, management, and control in rural Bangladesh: A qualitative study. Patient preference and adherence. 2018; 12:1437.

15. Melamed S, Froom P, Green MS. Hypertension and sickness absence: The role of perceived symptoms. Journal of Behavioral Medicine. 1997 Oct 1; 20(5):47387.

16. Middeke M, Lemmer B, Schaaf B, Eckes L. Prevalence of hypertension-attributed symptoms in routine clinical practice: a general practitioners-based study. Journal of human hypertension. 2008 Apr; 22(4):252.
17. Dimenäs ES, Wiklund IK, Dahlöf CG, Lindvall KG, Olofsson BK, De UF. Differences in the subjective well-being and symptoms of normotensives, borderline hypertensives and hypertensives. Journal of hypertension. 1989 Nov; 7(11):885-90.

18. Bulpitt CJ, Dollery CT, Carne S. Change in symptoms of hypertensive patients after referral to hospital clinic. Heart. 1976 Feb 1; 38(2):121-8.

19. Lee E, Park E. Self-care behavior and related factors in older patients with uncontrolled hypertension. Contemporary nurse. 2017 Nov 2; 53(6):607-21.

20. Middeke M, Lemmer B, Schaaf B, Eckes L. Prevalence of hypertension-attributed symptoms in routine clinical practice: a general practitioners-based study. Journal of human hypertension. 2008 Apr; 22(4):252.

21. Weiss NS. Relation of high blood pressure to headache, epistaxis, and selected other symptoms: The United States Health Examination Survey of Adults. New England Journal of Medicine. 1972 Sep 28; 287(13):631-3.

22. Munakata M, Hiraizumi T, Tomiie $T$, et al. Psych behavioral factors involved in the isolated office hypertension: comparison with stress-induced hypertension. J Hypertens. 1998; 16:419-4122.

23. Mann SJ. The clinical spectrum of labile hypertension: A management dilemma. The Journal of Clinical Hypertension. 2009 Sep; 11(9):491-7.

24. TRUE Consortium (in Ternationalconso Rtium for Ualityres Earch on dietary sodium/salt). Recommended standards for assessing blood pressure in human research where blood pressure or hypertension is a major focus. The Journal of Clinical Hypertension. 2017 Feb; 19(2):108-13.

\begin{tabular}{l} 
AUTHORSHIP AND CONTRIBUTION DECLARATION \\
\begin{tabular}{|c|l|l|}
\hline Sr. \# & \multicolumn{1}{|c|}{ Author(s) Full Name } & \multicolumn{1}{|c|}{ Contribution to the paper } \\
\hline 1 & Imtiaz Manzoor & Writing of the article \\
2 & Syed Jibran Ashraf & Analysis. \\
3 & Shahid Zafar & Drafting of article. \\
4 & Syeda Nosheen Zehra & Conception and obesign. \\
5 & Syed Naqeeb Ali & $\begin{array}{l}\text { Critical revisions and make } \\
\text { corrections. } \\
\text { Data collection. }\end{array}$ \\
\hline 6 & Momina Naseer &
\end{tabular} \\
\hline
\end{tabular}

